\title{
Comparison of decentralised and centralised computer-based production control
}

\author{
M. Weigelt
}

The Boston Consulting Group GmbH \& Partner, Sendlinger Strasse 7, 80331 München, Germany Telephone: 49-89 23 17 40; Fax: 49-89 2606698 E-mail:wsw190@wsrz2.wiso.uni-erlangen.de

\section{P. Mertens}

Universität Erlangen-Nürnberg, Betriebswirtschaftliches Institut, Bereich Wirtschaftsinformatik I, Lange Gasse 20 90403 Nürnberg , Germany

Telephone: 49 -911/5302 284; Fax: 49- 911/53 6634

E-mail:mertens@wiso.uni-erlangen.de

\begin{abstract}
In this article we present the main new features of the agent system DEPRODEX (Decentralised Production Control Expert) and its centralised counterpart ZEPRODEX. By testing these prototypes with more than 300 scenarios using a bicycle model plant we were able to compare several decentralised and centralised production control methods. Both conventional as well as new developed ones were evaluated. The results of these comparisons are judged concerning several factors of influence (e.g. complexity of manufacturing process, deviation of master scheduled flow-times etc.). This project is part of the special research organisation "Multiprocessor and Network Configurations" SFB 182 kindly sponsored by the DFG (Deutsche Forschungsgemeinschaft).
\end{abstract}

\section{Keywords}

Manufacturing, production control, scheduling, co-operating agents 


\section{PROBLEM SETTING}

Today, German industrial companies supporting production control by "leitstand" systems use decentralised and centralised concepts approximately to the same degree (Stadtler et al., 1993). While centralised methods aim at controlling the whole factory by only one leitstand, decentralised solutions assign one leitstand to each foreman area or even parts of it. In the latter case a network is formed leading to problems of co-ordination and optimisation among the individual leitstand systems (Scheer et al., 1991). Therefore the first question is how to improve decentralised methods by agent approaches using intelligent co-ordination mechanisms. The second question is - from an IT-perspective - to investigate under which circumstances centralised or decentralised production control should be preferred.

\section{DECENTRALISED APPROACHES}

Current leitstand systems just accept local tardiness of orders and pass the information to the next involved production areas (for a detailed analysis see (Weigelt, 1994, pp. 11). Even specially developed co-ordination modules work like this. Consequently, global tardiness at the end of the production process cannot often be avoided.

To overcome this problem we developed the agent-system DEPRODEX (Decentralised Production Control Expert). Here we distinguish two levels (see Figure 1): On the hierarchically higher control level, a so-called Job Order Agent (JOA) is specialised in co-ordinating the planning activities all over the factory. It receives master scheduled production orders and allots them to the several production areas, each managed by a so-called Machine Group Agent (MGA). Furthermore, the JOA provides information to the production manager on the current state of orders in the production process. On the hierarchically lower scheduling level, the MGAs are able to create schedules autonomously because functions and data are distributed completely. MGAs schedule by applying various priority rules and selecting the best plan afterwards. Being close to the production process, the foreman can consider current scheduling restrictions and therefore guarantee realistic plans. 


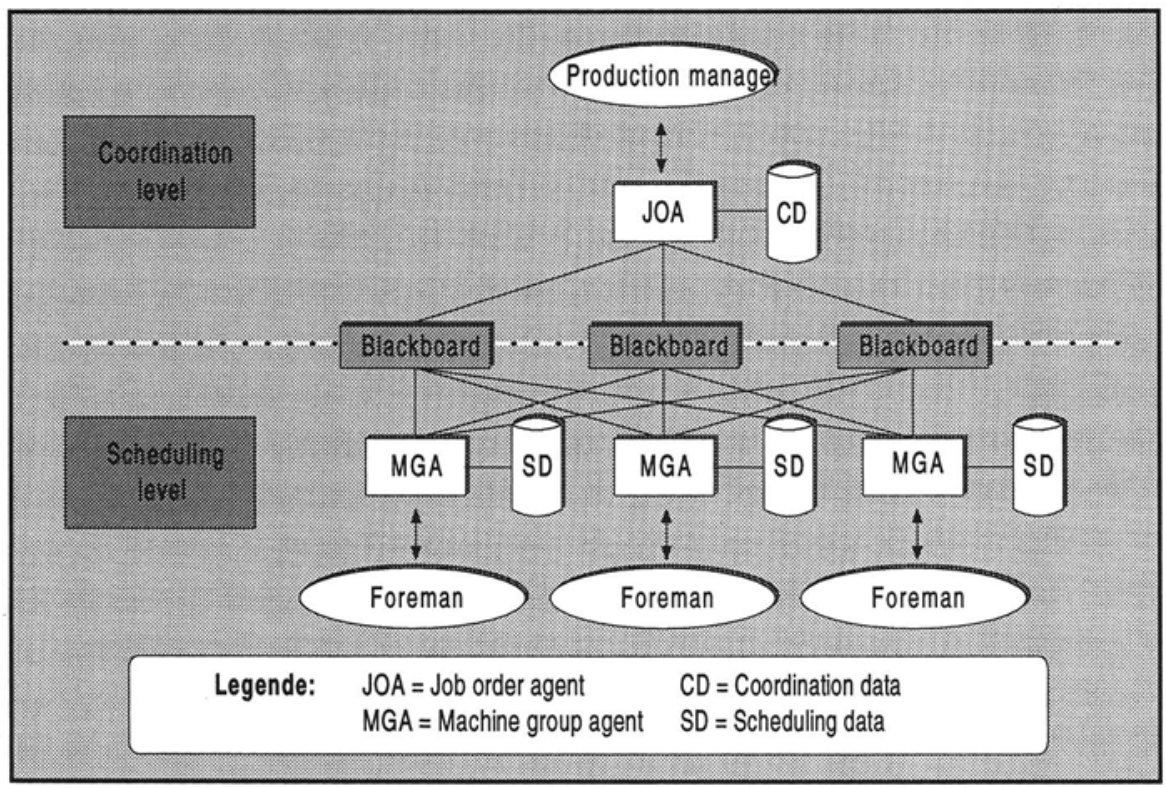

Figure 1: Architecture of DEPRODEX.

We worked out several co-ordination mechanisms to avoid global tardiness and to shorten flow-time and stock. They are all based on the intelligent exchange of unused buffer times. Whereas in DEPRODEX-1 the agents behave co-operatively, in the market mechanism of DEPRODEX-2 they act at least sometimes defectively. Both systems are founded on a blackboard architecture to support the extensive communication processes. They have been programmed on PCs in ToolBook and C for MS-Windows. For more details about the prototypes see (Weigelt et al., 1993; Weigelt, 1994).

\section{CENTRALISED APPROACHES}

To compare several decentralised and centralised production control methods, we implemented ZEPRODEX, a centralised counterpart of DEPRODEX concerning hard- and software. ZEPRODEX is an agent system encompassing two agents: A JOA with similar functionalities as in DEPRODEX and a so-called Machine Agent (MA) which generates schedules for the whole factory. The MA works and acts like a "big" MGA.

The centralised system consists of DEPRODEX modules as far as possible. In this way we could minimise implementation time and maximise comparability. 


\section{RESULTS}

To test and to compare the different methods in a realistic environment, we based our implementation on the data of a bicycle producing plant of the company Hercules $\mathrm{GmbH}$. Our model consists of three production areas including six machines each. In the decentralised approach one MGA is assigned to one production area, whereas in the centralised one the MA manages the whole plant.

The material flow through the factory depends on the nine different variants of bicycles. By creating adequate production programs we could investigate job-shop as well as flow-shop problems.

Table 1 Survey of considered scheduling methods

\begin{tabular}{|c|c|}
\hline Scheduling approach & Explanation \\
\hline Personal & $\begin{array}{l}\text { Personal scheduling (using knowledge of } \\
\text { setup-times) }\end{array}$ \\
\hline Decentralised conventional & $\begin{array}{l}\text { Milestones for each production area; app } \\
\text { various priority rules inside each area (sp }\end{array}$ \\
\hline DEPRODEX-1 & $\begin{array}{l}\text { Agent system mainly based on co-operat } \\
\text { behaviour }\end{array}$ \\
\hline DEPRODEX-2 & $\begin{array}{l}\text { Agent system mainly based on defective } \\
\text { behaviour }\end{array}$ \\
\hline Centralised conventional & $\begin{array}{l}\text { Applying various priority rules for the w } \\
\text { production (spectrum) }\end{array}$ \\
\hline ZEPRODEX-1 & $\begin{array}{l}\text { Transformed and modified algorithm of } \\
\text { DEPRODEX-1 (centralised version) }\end{array}$ \\
\hline ZEPRODEX-2 & $\begin{array}{l}\text { Transformed and modified algorithm of } \\
\text { DEPRODEX-2 (centralised version) }\end{array}$ \\
\hline
\end{tabular}

Table 1 gives a survey of the different scheduling methods considered in our tests. The conventional approaches are represented by a spectrum of solutions, because each priority rule produces an individual result, and it cannot be predicted which one attains current scheduling goals best. Therefore we used the best and the worst value in each case to have benchmarks for our new developed solutions. 
For measuring the quality of scheduling methods, we used the classical goals

- $\quad$ minimising tardiness;

- minimising flow-time and

- $\quad$ minimising stock.

In contrast to this, capacity load has not been a primary goal because we always explored the production of orders through the whole factory. Consequently, capacity load became a predefined Figure influenced by the due-dates.

We carried out tests with ten scenarios, each represented a different production situation depending on scheduling complexity, capacity load, short-term breakdowns, a. s. o. In about 300 planning courses we scheduled approximately 1000000 operations to compare the several scheduling methods. Figure 2 illustrates the average results considering all scenarios.

From a general point of view the results can be summarised by three statements:

The new developed co-ordination mechanisms improve decentralised scheduling to a high extent. In average, tardiness can be reduced by $50 \%$, flowtime by $25 \%$, and stock by $38 \%$ applying the co-ordination procedures among the agents. There was no scenario in which the new solutions were worse than the conventional ones. In both projects - DEPRODEX-1 and DEPRODEX-2 - we were able to prove the convergence of our co-ordination mechanisms.

- The general question whether production scheduling should be performed by a centralised or a decentralised system must be answered carefully. Focusing on tardiness a decentralised agent approach is the most promising method. But if the main goal is minimising flow-time and/or stock, centralised scheduling achieves the best results - assuming all constraints can be considered and there is no need to modify the schedule by the foremen.

- If you really want to optimise production control, personal scheduling cannot be an adequate alternative. In none of our test-scenarios personal scheduling achieved better results than computer-based methods. On an average, the agent systems could avoid $90 \%$ of the delays personal scheduling caused. Flow-time and stock was reduced by $40 \%$ respectively $54 \%$ using the coordination mechanisms. 


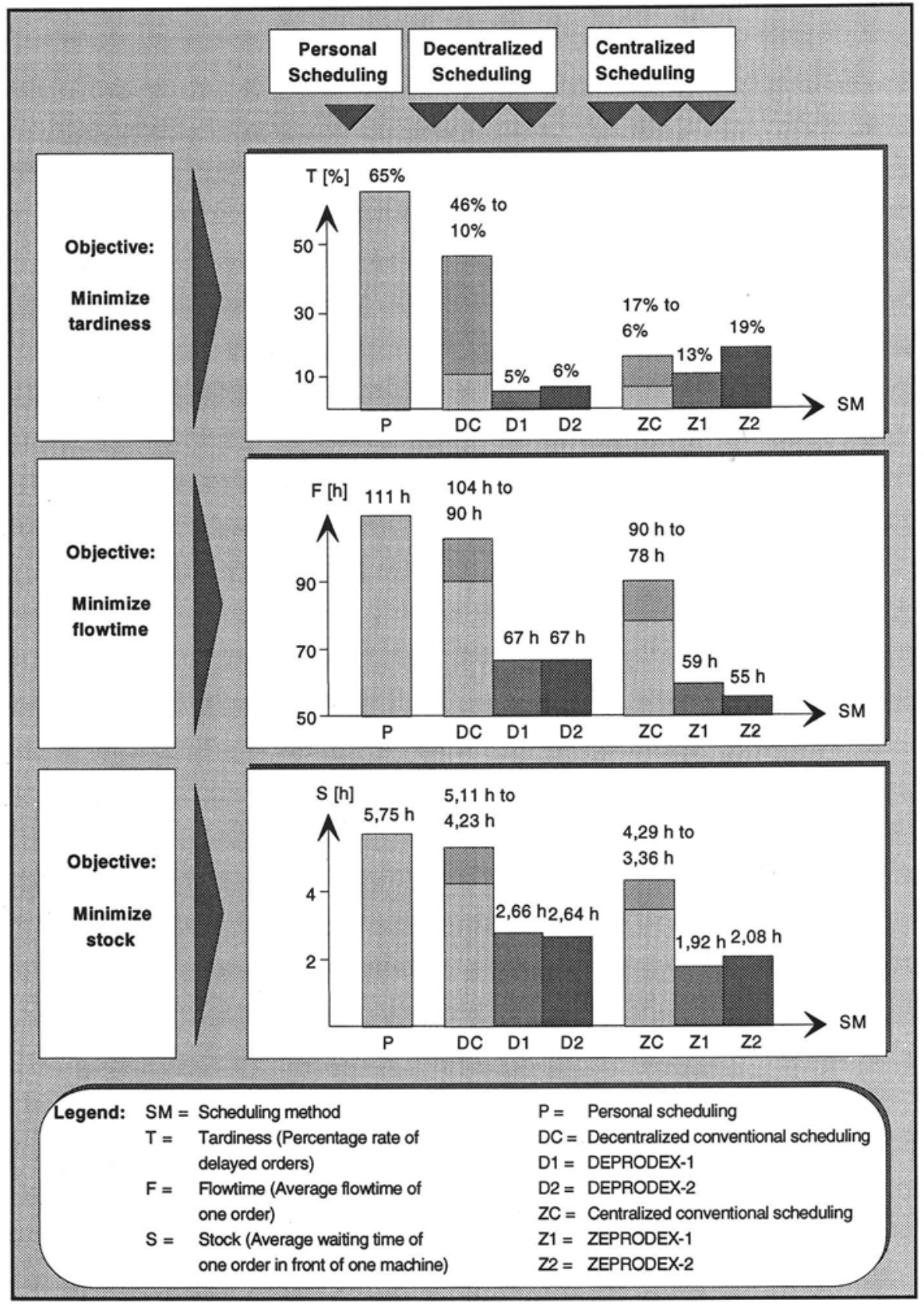

Figure 2: Test results with DEPRODEX and ZEPRODEX. 
Taking a look on the detailed analysis, it must be emphasised that the master scheduled due-dates have a big influence on the results (see Figure 3). Of course, if you reduce master scheduled flow-time, danger of tardiness increases. But, DEPRODEX-1 proves its benefits by achieving even the lowest percentage of delayed orders. Considering flow-time there is another interesting effect. The shorter the flow-time is planned in advance, the less the quality of the various scheduling methods differs. Here the advantage of the agent approach is more obvious in the case of long master scheduled flow-time. Focusing on stock we achieved quite similar results. We can state that in both cases the decentralised agent approach produces better results than the conventional methods at least concerning one of the objectives.

Another influence factor which has to be mentioned is production complexity. On the one hand, quality of conventional decentralised scheduling improves in comparison to the centralised approaches when complexity of the whole production process increases. On the other hand, the new co-ordination mechanisms work less successful in this case. As a conclusion, the agent solution fits best in a middle range of production complexity.

One of the most important results concerns short-term breakdowns. Here the agent solutions achieve values above average whereas conventional decentralised scheduling have to accept very bad marks.

At last two special advantages of the agent systems shall be pointed out which could be proven during the tests:

- DEPRODEX-1 and ZEPRODEX-1 allow refined judgement of generated schedules. It is possible to distinguish whether flow-time reductions can be achieved by advanced finishing dates, postponed starting dates, or both. Using a special classification of orders prevents e. $g$. that too early finished production orders are valued positively because of the saved flow-time.

- DEPRODEX-2 and ZEPRODEX-2 allow "order-individual scheduling". That means that an order will be preferred to this extent as its external priority number relates to the other priority numbers. E. g. a special order may have a three times higher priority number than an average order. In case of trouble this causes that three hours delay of an average order is equalised by one hour delay of the special order. Consequently, the production manager has much more transparency what "price" special orders really cost. 


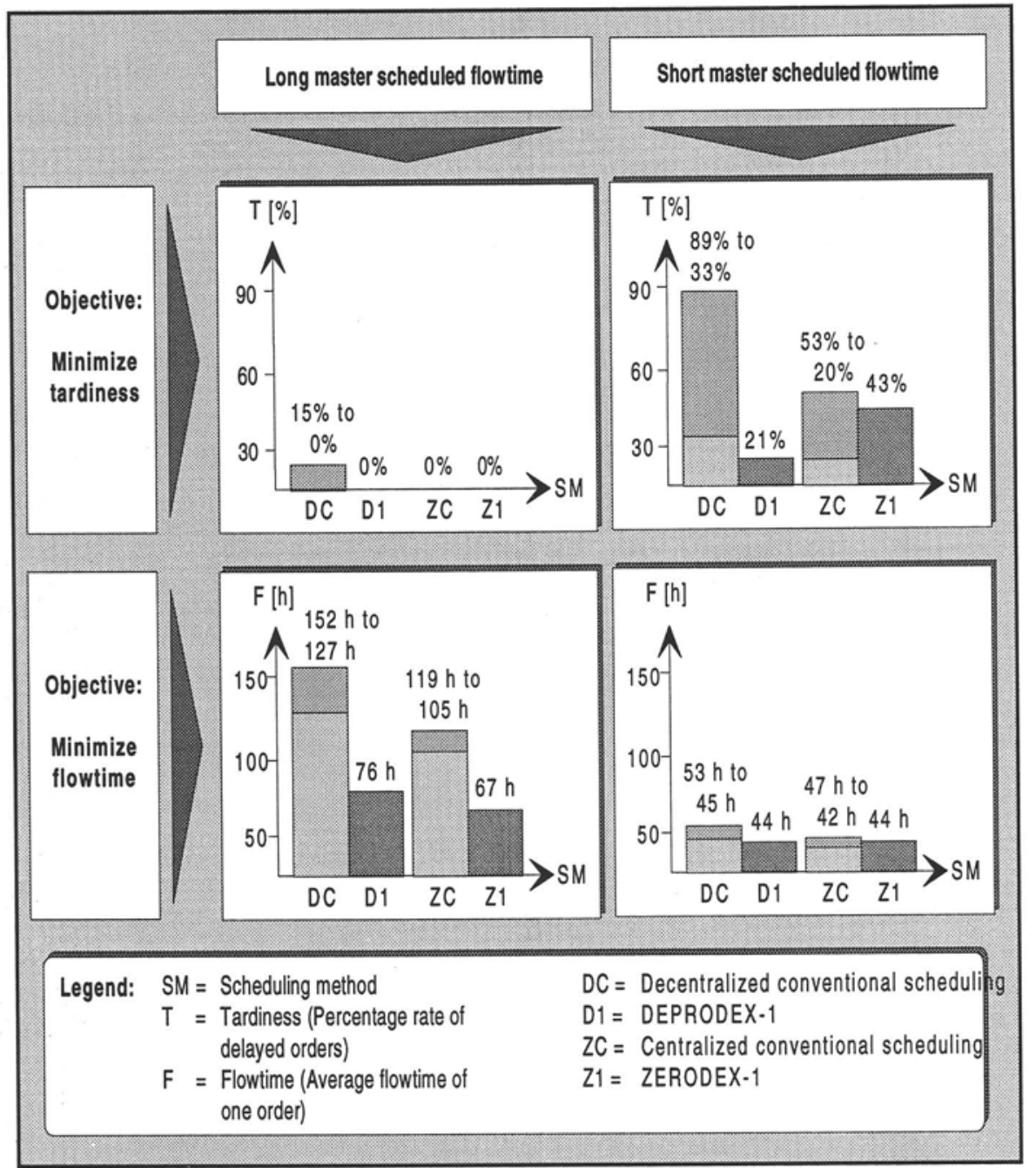

Figure 3: Influence of master scheduled flow-time.

\section{CONCLUSION}

In general, the discussion proves good up to very good results of agent systems in comparison to other approaches. Having a broader view including the numerous organisational advantages of decentralised concepts an agent approach for production control shall be supported. To achieve even better results, a mixed 
centralised/decentralised solution - as well realised as an agent system - seem to be promising (Weigelt (1994), p. 119).

\section{REFERENCES}

Scheer, A.-W. and Hars, A., 1991, The Leitstand - A New Tool for Decentral Production Control, in: Fandel, G. and Zäpfel, G. (Eds.), Modern Production Concepts (Berlin), 370-385.

Stadtler, H. and Wilhelm, S., 1993, Einsatz von Fertigungsleitständen in der Industrie, Zeitschrift für wirtschaftliche Fertigung 9/1, 39-44.

Weigelt, M. and Mertens, P., 1993, Production Control with Distributed Knowledge-Based Systems, Journal of Information Science and Technology $3 / 2,200-211$.

Weigelt, M., 1994, Weiterentwicklung der dezentralen Produktionssteuerung unter besonderer Berücksichtigung von Agenten-Systemen und Vergleich mit zentraler Regelung (Nuernberg), $\mathrm{PhD}$ Thesis.

\section{BIOGRAPHIES}

Peter Mertens was born in 1937, he is the director of the Department for Information Systems Research at the University of Erlangen-Nuremberg, Germany. He is the deputy-spokesperson of the executive committee at the Bavarian Research Institute for Knowledge-based Systems (FORWISS). He is also the editor-in-chief of WIRTSHAFTSINFORMATIK, a German scientific journal dedicated to Information Systems Research. Professor Mertens graduated from the Technical University of Darmstadt, Germany with a degree in industrial engineering. He worked at several universities before joining a major ITconsulting firm, at first in a management position, later as managing director. His main research interests are: IS in marketing, production, logistics and controlling; MIS; Expert Systems; Data Mining; Workflow Management Systems; Industryspecific application architectures; Virtual enterprises.

Mark Weigelt was born in 1965, he joined the Munich office of the Boston Consulting Group in 1994. Prior to joining BCG, he spent internships at Deutsche Bahn AG, Siemens AG, Imperial Chemical Industries GB, Gemini Consulting and worked for three years as research assistant at University of Erlangen-Nürnberg with a focus on technical development. During his time with the Boston Consulting Group, Mark participated in projects in the industrial goods and financial services sector. Mark studied electrical engineering and business administration and holds a $\mathrm{PhD}$ in business administration from the University of Erlangen- Nürnberg, Germany. 